\title{
Macrophage activation in exacerbated COPD with and without community- acquired pneumonia
}

\author{
P. Gutierrez*, D. Closa*, R. Piñer", O. Bulbena*, R. Menéndez ${ }^{\star}$ and A. Torres ${ }^{\#}$
}

ABSTRACT: In large series of nonresponding community-acquired pneumonia (CAP) patients, chronic obstructive pulmonary disease (COPD) was observed to be a protective factor for nonresponse to initial antibiotics. This intriguing fact may be linked to changes in the phenotype of inflammatory cells and, in particular, to the induction of classical-M1 or alternative-M2 activation of macrophages, which result in different inflammatory profiles.

We evaluated the effect of sputum obtained from patients with acute exacerbation of COPD (AECOPD), CAP and COPD+CAP on the phenotypic changes in macrophages. Human THP1 cells differentiated to macrophages were incubated with sputum from patients with AECOPD, CAP or COPD+CAP, and expression of tumour necrosis factor- $\alpha$, interleukin-6, mannose receptor and arginase was measured to evaluate the phenotype acquired by macrophages. We found that sputum from CAP patients induced the M1 phenotype and that from AECOPD patients induced an M2-like phenotype. Sputum from CAP+COPD patients did not present a clear M1 or M2 phenotype.

These results indicate that the microenvironment in the lung modulates the activation of macrophages, resulting in different phenotypes in AECOPD, CAP and COPD+CAP patients. This different type of activation induces different inflammatory responses and may be involved in the different outcome observed when COPD and CAP present simultaneously.

KEYWORDS: Chronic obstructive pulmonary disease, community-acquired pneumonia, inflammation, macrophages, sputum

ommunity-acquired pneumonia (CAP) is a common cause of acute illness in adults and one of the most frequent causes of hospital admission associated with significant mortality rates. The mortality rate is very high among hospitalised patients, ranging from $5 \%$ to $15 \%$, and represents the most frequent infectious cause of death among patients of all ages [1].

In these patients, the principal risk factors for acquiring CAP are old age and pulmonary comorbidities such as chronic obstructive pulmonary disease (COPD). Indeed, CAP is a frequent event in the course of COPD, a fact explained mainly by the abnormal pulmonary defence mechanisms. For this reason, a number of clinical and epidemiological studies have been carried out in order to determine whether COPD was a predictor of increased mortality in patients hospitalised due to pneumonia.

Surprisingly, some studies did not find differences in 30-day mortality when comparing COPD patients with non-COPD patients with CAP [2].
This is an intriguing finding, as one would expect a higher mortality in such a severe population, and is a finding that has generated debate in clinical practice [3-5]. Furthermore, in a recent study of patients with antibiotic treatment failure, MENÉNDEZ et al. [6] found that, in a large series of nonresponding CAP patients, COPD was a protective factor for nonresponse to initial antibiotics. Similarly, it has recently been reported that, in a series including thousands of hospitalised CAP patients, the mortality of COPD was the lowest $(10 \%)$ compared with a series of comorbidities that even reached $25 \%$ mortality [7].

There may be several explanations for this. First, it is known that in up to $50 \%$ of COPD patients, the lower airways have an increased inflammatory status linked to the colonisation of the lower airways by pulmonary pathogens [8]. This status is related to changes in cytokines such as tumour necrosis factor (TNF)- $\alpha$ or interleukin (IL) -6 and other inflammatory mediators, and also with the cellular stress response and the generation

\section{AFFILIATIONS}

*Dept Experimental Pathology, Institut d'Investigacions Biomèdiques de Barcelona, Consejo Superior de Investigaciones Científicas IIBBCSIC, Insitut d'Investigacions Biomèdiques August Pi i Sunyer (IDIBAPS),

\#Pneumology Dept, Clinic Institute of Thorax, Hospital Clinic of Barcelona, Insitut d'Investigacions Biomèdiques August Pi i Sunyer (IDIBAPS), University of Barcelona, Ciber de Enfermedades Respiratorias

(Ciberes), and

"Pneumology Service, Universitary Hospital La Fe, Ciber de

Enfermedades Respiratorias (Ciberes CB06/06/0028), el Ciberes es una iniciativa del ISCIII, Barcelona, Spain.

CORRESPONDENCE

A. Torres

Pneumology Dept

Clinic Institute of Thorax (ICT)

Hospital Clinic of Barcelona

Villarroel

1708036 Barcelona

Spain

E-mail: atorres@clinic.ub.es

Received:

July 272009

Accepted after revision:

Dec 022009

First published online:

Dec 232009

European Respiratory Journal

Print ISSN 0903-1936

Online ISSN 1399-3003 
of anti-inflammatory and protective mediators. This different microenvironment may produce a protective effect against bacterial attack.

Another possible factor is the acute administration of steroids that also inhibits the inflammatory response, thereby modifying the interactions between COPD and CAP [9]. We do not have clinical data regarding the percentage of hospitalised COPD patients who receive steroids in clinical practice. However, in a study designed to evaluate the effect of steroids, CONFALIONIERI et al. [10] observed that, in severe CAP, hydrocortisone infusion attenuates systemic inflammation and leads to earlier resolution of pneumonia and a reduction in sepsisrelated complications and mortality.

In the regulation of inflammation, macrophages play a central role in modifying the duration and magnitude of the inflammatory response. These cells may adopt different phenotypes induced by different stimuli. The classically activated (M1) macrophages promote inflammation, extracellular matrix destruction and bactericidal activities. In contrast, the alternatively activated (M2) macrophages promote tissue regeneration, angiogenesis, cell proliferation and inhibition of the inflammatory response [11].

In CAP patients, the classical M1 macrophage phenotype is induced by bacterial products and the cytokines involved in the initial inflammatory response. In contrast, alveolar macrophage activation in COPD patients appears to be more complex. This is because inflammation, airway remodelling and parenchymal destruction are established features of COPD and include both M1 (inflammation) and M2 (remodelling) stimuli. However, some reports indicate that a downregulation of M1 genes and a gradual upregulation of some M2-related genes can be observed in COPD patients [12].

This polarised response between CAP and COPD in terms of macrophage activation is the consequence of different microenvironmental conditions in these pathological conditions. Thus, it could be suspected that the combination of COPD and CAP will result in a particular lung environment and in a particular stimulus for macrophage activation. Since this different inflammatory status may be an explanation for the protective effect of COPD it may be important to evaluate the effect of mediators present in the airways of this particular group of patients on the activation of macrophages. Despite the differences with respect to bronchoalveolar lavage [13], induced sputum has been shown to be a reproducible noninvasive approach for determining the presence of inflammatory cells and mediators in the airways of the lungs [14].

In this study, we designed a series of experiments to evaluate the effect of the microenvironment in the lungs on modulating the inflammatory response. For this purpose, we measured the effect of sputum obtained from patients with acute exacerbation of COPD (AECOPD), CAP and COPD+CAP on the phenotypic changes on macrophages in vitro.

\section{MATERIAL AND METHODS}

\section{Study design}

In the initial experiment, we evaluated the effect of mediators present in the lung microenvironment of patients with
$\mathrm{CAP}+\mathrm{COPD}$ on the activation of macrophages. We compared this activation with that obtained from patients with only COPD or CAP. For this purpose, cultured macrophages from the human macrophage cell line THP1 were incubated with sputum obtained from patients corresponding to groups $\mathrm{CAP}+\mathrm{COPD}, \mathrm{CAP}, \mathrm{COPD}$ or control. Sputum was filtered in order to remove bacteria, viruses or cell debris, thus ensuring that the phenotypic changes observed were induced only by soluble mediators. An unstimulated cell line was used instead of alveolar macrophages from patients in order to avoid possible interference by previous activations due to pharmacological treatments or environmental pollutants.

In the next experiment, we evaluated how the bacterial products modify the response of macrophages to COPD mediators. THP1 cells incubated with sputum from COPD patients were also treated with lipopolysaccharide (LPS), and the resulting phenotypes were compared with that obtained in the absence of LPS. Finally, the HL-60 macrophage cell line, which does not express CD14 (a co-receptor along with Toll-like receptor (TLR)4 for the detection of LPS in leukocytes), was used to evaluate the phenotypic changes induced not by bacterial products but by other mediators present in sputum.

\section{Patients and controls}

We included three types of patients: 1) COPD patients with CAP requiring hospitalisation; 2) exacerbated COPD patients without CAP; and 3) CAP hospitalised patients without COPD.

Controls were defined as healthy individuals that did not have any of the above conditions.

CAP was defined as a new infiltrate in chest radiograph and at least two compatible clinical symptoms (fever, cough, expectoration, pleuritic chest pain) [15]. Exclusion criteria for enrolling patients were patients admitted in the previous 15 days, patients undergoing treatment with cytostatic and/or other immunosuppressive therapy and HIV-positive patients.

COPD was defined according to a functional respiratory criteria (forced expiratory volume in $1 \mathrm{~s}$ (FEV1) $<70 \%$, FEV1 bronchodilator test $<60 \%$, and $\mathrm{FEV} 1 /$ forced vital capacity $<70 \%$ measured before hospitalisation), together with an age of $>20$ yrs, a history of smoking at least of 20 pack-yrs and a compatible clinical history [16]. Acute exacerbation was defined according to the criteria of ANTHONISEN et al. [17], which includes increased dyspnoea, sputum volume and purulence (Anthonisen type I exacerbation). All patients from the three groups were hospitalised on the decision of the attending physician. All patients (COPD with pneumonia, exacerbated COPD without pneumonia and pneumonia without (OPD) were treated with antibiotics according to local guidelines. All patients with exacerbated COPD without pneumonia received intravenous steroids for between 3 and 5 days and dosages were then gradually reduced (initial dosage $60 \mathrm{mg} \cdot 12 \mathrm{~h}^{-1}$ ). All samples were obtained during the first $24 \mathrm{~h}$ after admission and before the administration of steroids. We studied a total of 49 cases, of which 16 had an acute exacerbation of COPD without pneumonia, 11 had COPD and CAP, 15 had CAP without COPD, and seven were control patients (table 1). 
TABLE 1 General characteristics of patients studied

\begin{tabular}{|c|c|c|c|c|}
\hline & Controls & AECOPD & CAP & COPD + CAP \\
\hline Subjects n & 7 & 16 & 15 & 11 \\
\hline Sex $M / F n$ & $4 / 3$ & $14 / 2$ & $10 / 5$ & $9 / 2$ \\
\hline Nonsmokers & 71.4 & 0 & 28.6 & 11.1 \\
\hline Smokers & 28.6 & 35.7 & 28.6 & 11.1 \\
\hline FVC/FEV 1 & & $53.78 \pm 15.07$ & & $66.12 \pm 26.63$ \\
\hline
\end{tabular}

\section{Sample collection}

Sputum from patients was obtained from spontaneous cough within the first $24 \mathrm{~h}$. Gram stain and sputum culture was processed only if the sample was adequate. Sputum was considered valid if the sample contained $>25$ leukocytes and $<10$ epithelial cells per field (100).

In the induced sputum in the control group, sputum production was induced by inhalation of a $5 \%$ hypertonic saline solution for between 5 and $10 \mathrm{~min}$. Hypertonic saline was delivered by a nebuliser device (Ultraneb 2000; DeVilbiss Healthcare Inc., Somerset, PS, USA) attached to an oxygen supply. Subjects were then encouraged to cough and expectorate in a sterile plastic container.

Macroscopic saliva was removed and samples were collected in an Eppendorf tube. The volume of the sputum was measured and a volume of Sputolysin (Calbiochem-Behring, La Jolla, CA, USA) was added to the sputum in proportion of 1:4, the sample was shaken for $15 \mathrm{~min}$ at room temperature and then filtered through a $48-\mu \mathrm{m}$ nylon mesh to remove mucus and squamous cells. The suspension was then centrifuged at $750 \times g$ for $10 \mathrm{~min}$. The supernatant was collected and $500 \mu \mathrm{L}$ were filtered in a Vivaspin $100 \mathrm{~K}$ spin concentrator in order to remove bacteria, viruses and cell debris. Finally, the sample was stored at $-70^{\circ} \mathrm{C}$ for subsequent analysis.

\section{Cell culture}

Human monocyte THP1 and HL60 myeloid leukaemia cell lines were cultured in suspension in RPMI 1640 medium supplemented with $10 \%$ fetal calf serum, $2 \mathrm{mM}$ L-glutamine, $100 \mathrm{U} \cdot \mathrm{mL}^{-1}$ penicillin and $100 \mu \mathrm{g} \cdot \mathrm{mL}^{-1}$ streptomycin in a humidified atmosphere of $95 \%$ air, $5 \% \mathrm{CO}_{2}$ at $37^{\circ} \mathrm{C}$. Cells were differentiated to macrophages by a first incubation with $0.16 \mathrm{mM}$ phorbol 12-myristate 13-acetate (PMA; Sigma Chemical Co., St. Louis, MO, USA) for $48 \mathrm{~h}$ at $37^{\circ} \mathrm{C}$ in plastic Petri dishes (Nunclon; Nunc Inc., Naperville, IL, USA). PMA was removed $24 \mathrm{~h}$ before the experiments. This treatment results in the induction of a macrophage-like phenotype for these cell lines $[18,19]$.

In initial experiments, sputum from patients with COPD or CAP was added in duplicate to the media at a concentration of $20 \%$, and THP1 or HL60 cells were incubated for $24 \mathrm{~h}$. After incubation, RNA was obtained and the expression of markers for M1 and M2 phenotypes was analysed. In subsequent experiments, the effect of sputum from patients with COPD+CAP was also evaluated. Saline solution treated with Sputolysin and processed as sputum was used for the control samples.

In some experiments, LPS (Escherichia coli 0111:B4) (Sigma Chemical Co.) was added to a final concentration of $100 \mathrm{ng} \cdot \mathrm{mL}^{-1}$.

\section{RNA extraction and RT-PCR}

Total RNA from cells was extracted using the TRIzol® reagent (Invitrogen, Carlsbad, CA, USA). $1 \mu \mathrm{g}$ total RNA was used for amplification using the Invitrogen One Step RT-PCR System according to the manufacturer's instructions. The following primers were used: TNF- $\alpha$ forward $5^{\prime}$-cttctcttcctgatcgtgg- $3^{\prime}$ and reverse $5^{\prime}$-gctggttatctctcagctcca-3'; IL-6 forward $5^{\prime}$-aaa gaggcactggcagaaaa-3' and reverse $5^{\prime}$-gaggtgcccatgctacattt-3'; mannose receptor forward $5^{\prime}$-tgacacacttttggggatca- $3^{\prime}$ and reverse $5^{\prime}$-aaacttgaacgggaatgcac $-3^{\prime}$. Fragments were amplified using 30 35 cycles of PCR, with each cycle consisting of $15 \mathrm{~s}$ at $94^{\circ} \mathrm{C}, 30 \mathrm{~s}$ at $55^{\circ} \mathrm{C}$, and $1 \mathrm{~min}$ at $72^{\circ} \mathrm{C}$. The resulting RT-PCR products were electrophoresed on $2 \%$ agarose gels with DNA markers, stained with ethidium bromide, and viewed under ultraviolet light. Glyceraldehyde 3-phosphate dehydrogenase was used as an internal control for stable expression (housekeeping gene): the forward primer was $5^{\prime}$-tcctctgacttcaacagcgacacc- $3^{\prime}$ and the reverse primer was $5^{\prime}$-tctctcttcctcttgtgctcttgc-3'. The publicdomain software ImageJ version 1.32 was used to quantify the intensities of the bands obtained.

\section{Cell viability}

The cytotoxic effects of different sputums on macrophages were quantified using a 3-(4,5-dimethylthiazole 2-yl)-2,5 diphenyl-tetrazolium bromide (MTT) cellular proliferation assay (Chemicon International, Inc., Temecula, CA, USA). Cells were seeded at $1 \times 10^{4}$ cells.well $^{-1}(0.1 \mathrm{~mL})$ on a 96-well plate and incubated with sputum for $24 \mathrm{~h}$ at $37^{\circ} \mathrm{C}$. Then, the cells were incubated for a further $2 \mathrm{~h}$ with $0.02 \mathrm{~mL}$ MTT reagent at $37^{\circ} \mathrm{C}$. After incubation, absorbance was measured by spectrophotometry at $570 \mathrm{~nm}$. 


\section{Statistical analysis}

Data are expressed as mean \pm SEM. Means of different groups were compared using a one-way ANOVA. The Tukey multiple comparison test was performed to evaluate significant betweengroup differences. Differences were assumed to be significant when $\mathrm{p}<0.05$.

\section{RESULTS}

\section{Patients}

We studied 49 cases of which 16 had AECOPD without pneumonia, 11 had COPD+CAP, 15 had CAP without COPD and seven were control patients. All AECOPD patients were class I or II according to the Anthonisen criteria [17]. The main general characteristics of these patients are shown in table 1.

Patients with CAP (both with and without COPD) were treated with levofloxacin or with the combination of a $\beta$-lactam plus a macrolide (usually cefttriaxone + azitrhomycin) All patients with exacerbated COPD without pneumonia received intravenous steroids for 3-5 days and dosages were then gradually reduced (initial dosages: $60 \mathrm{mg}$ per $12 \mathrm{~h}$ ). All patients in all the three categories survived.

\section{Cell viability}

Macrophages treated with increasing concentrations (up to $40 \%$ ) of sputum do not show changes in cell viability.
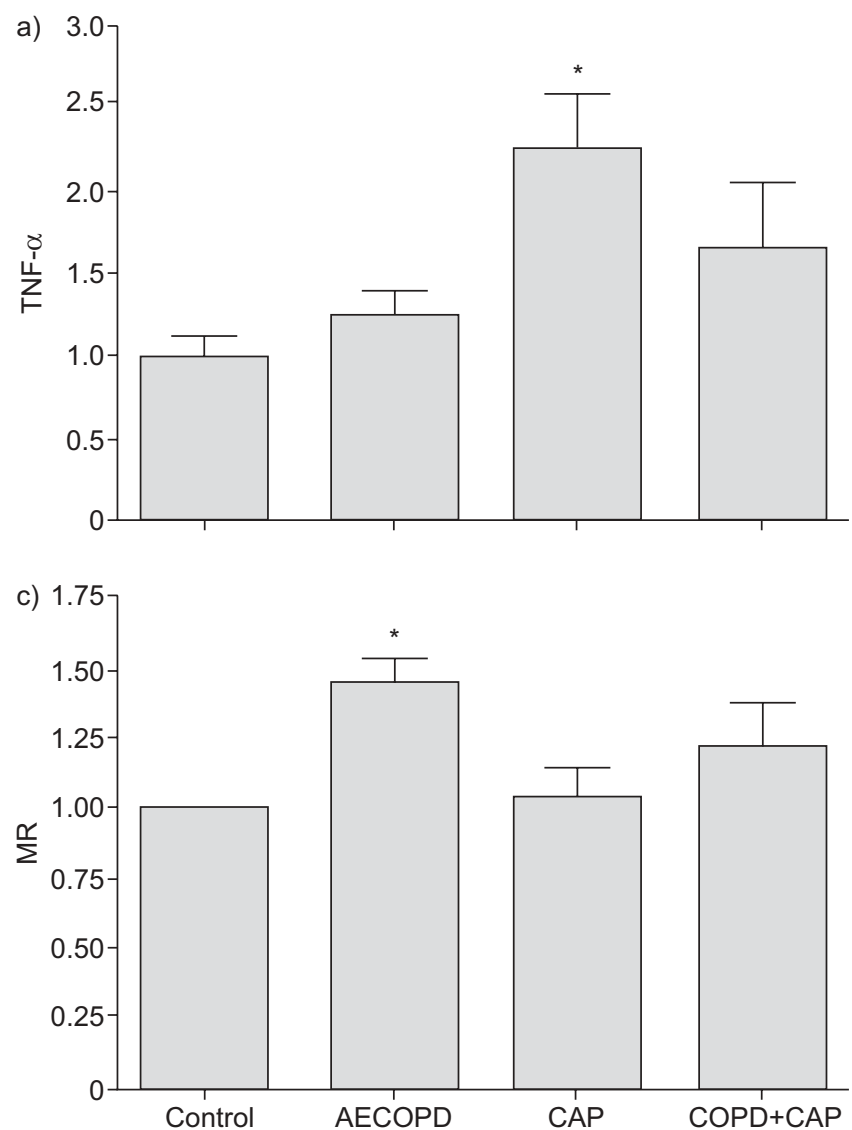

Consequently, a $20 \%$ sputum concentration in cell culture media was used in all the experiments.

\section{Changes in macrophage phenotype}

Macrophage differentiated THP1 cells treated with AECOPD sputum showed an increased expression on the mannose receptor as well as arginase mRNA (fig. 1). However, despite the absence of an observed increase in TNF- $\alpha$ expression, IL-6 showed significantly increased induction. This result is similar, but not identical, to what would be expected during an M2 differentiation. Moreover, CAP sputum induces an M1 response in these cells, characterised by the lack of changes in mannose receptor or arginase and significant increases in both TNF- $\alpha$ and IL-6 expression. Finally, in cells treated with sputum obtained from patients with CAP+COPD, a significant increase was observed only in IL-6. Increases in mannose receptor, TNF- $\alpha$ and arginase were observed but were not significant.

\section{Effect of LPS on cytokine expression}

The induction of IL-6 in macrophages treated with AECOPD sputum may be linked to the presence of low levels of bacterial products. To evaluate this possibility, we analysed the effect of LPS in cells treated with AECOPD sputum. As expected, LPS induced the expression of IL- 6 and TNF- $\alpha$ in control cells (fig. 2). No additional IL-6 induction was observed in
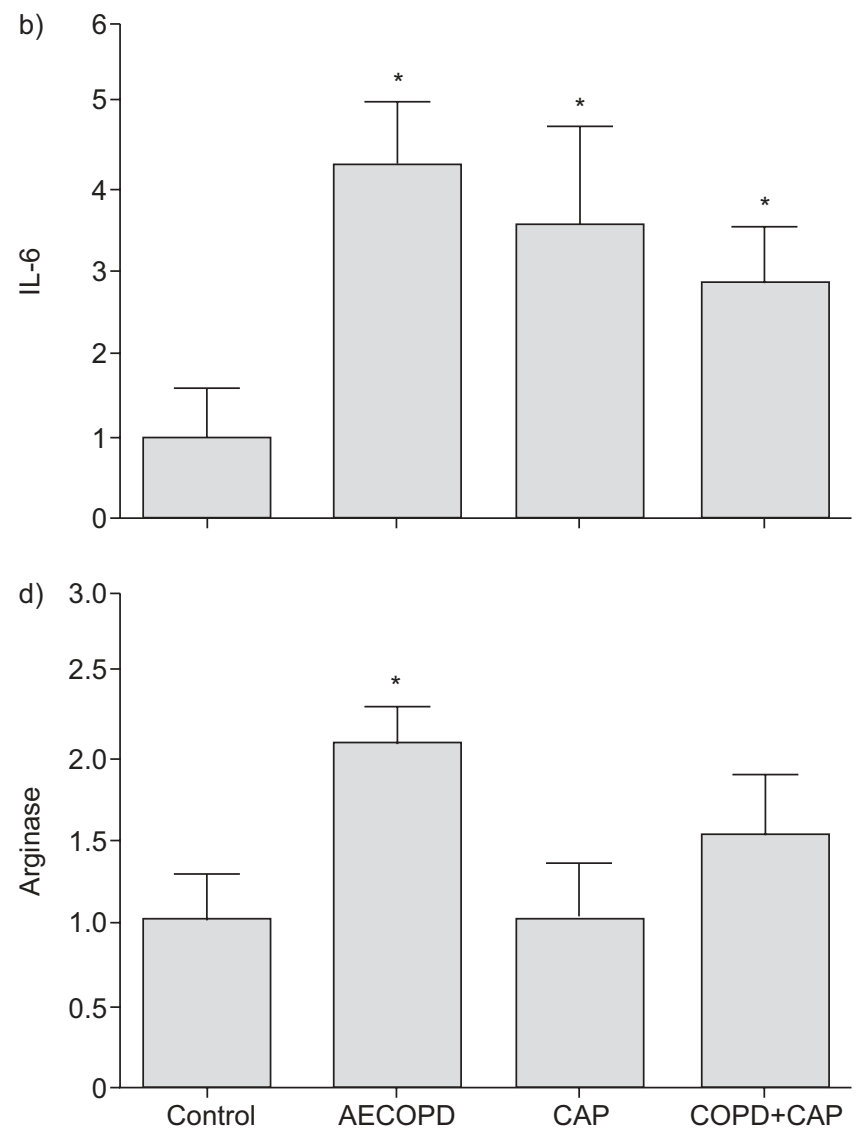

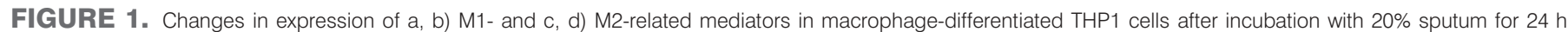

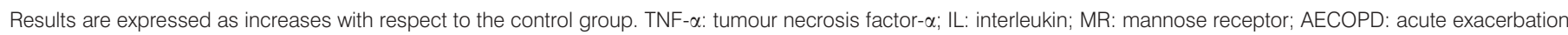
of chronic obstructive pulmonary disease (COPD); CAP: community-acquired pneumonia. *: $p<0.05$ with respect to control. 

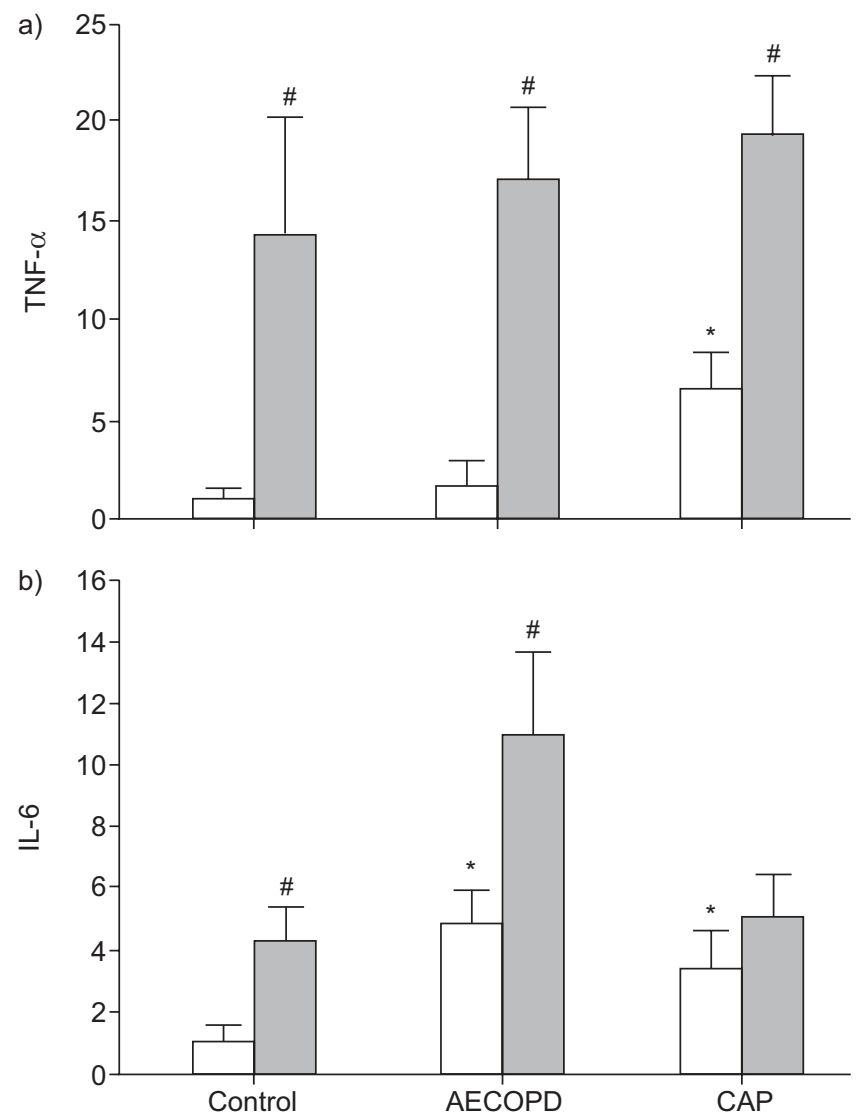

FIGURE 2. Effect of lipopolysaccharide (LPS; $100 \mathrm{ng} \cdot \mathrm{mL}^{-1}$ ) treatment on macrophage-differentiated THP1 cells incubated with 20\% sputum for $24 \mathrm{~h}$. Results are expressed as increases with respect to the control group. TNF- $\alpha$ : tumour necrosis factor- $\alpha$; IL: interleukin; AECOPD: acute exacerbation of chronic obstructive pulmonary disease; CAP: community-acquired pneumonia. $\square$ : nontreated; 1 : LPS treated. *: $p<0.05$ with respect to control; $: p<0.05$ with respect to nontreated cells.

CAP-treated cells, but a significant increase was found in AECOPD-treated cells, suggesting the involvement of different mechanisms between COPD and CAP activation.

Activation in the presence of CAP sputum may be linked to the presence of microbial products in the medium. As CD14 acts as a co-receptor, along with TLR4, to detect LPS in leukocytes, we evaluated the effects on HL60 cells, a cell line similar to THP1 but which, when differentiated to macrophages, does not express CD14 (fig. 3a). When the same experiment was carried out in HL60 cells (figs 3b and c), no additional increases were observed in AECOPD treated cells.

\section{DISCUSSION}

The main finding of this study was the observation that the microenvironment present in the lung may modify the progression of the inflammatory response by inducing a different macrophage-activation phenotype in AECOPD, CAP or COPD+ CAP patients. The progression of CAP and COPD generates different pathophysiological situations. Consequently, the response induced by the defence mechanisms in the lung could be expected to be highly different, resulting in clearly differentiated lung microenvironments. However, when these two pathological processes occur simultaneously, the resulting cell environment in a)

PMA

CD14

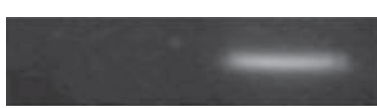

THP1

HL60
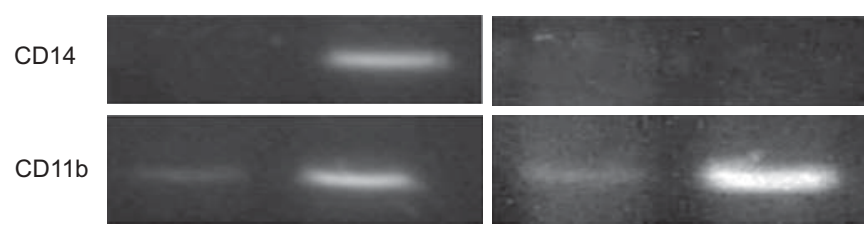

GAPDH
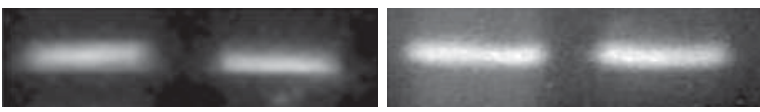

b)
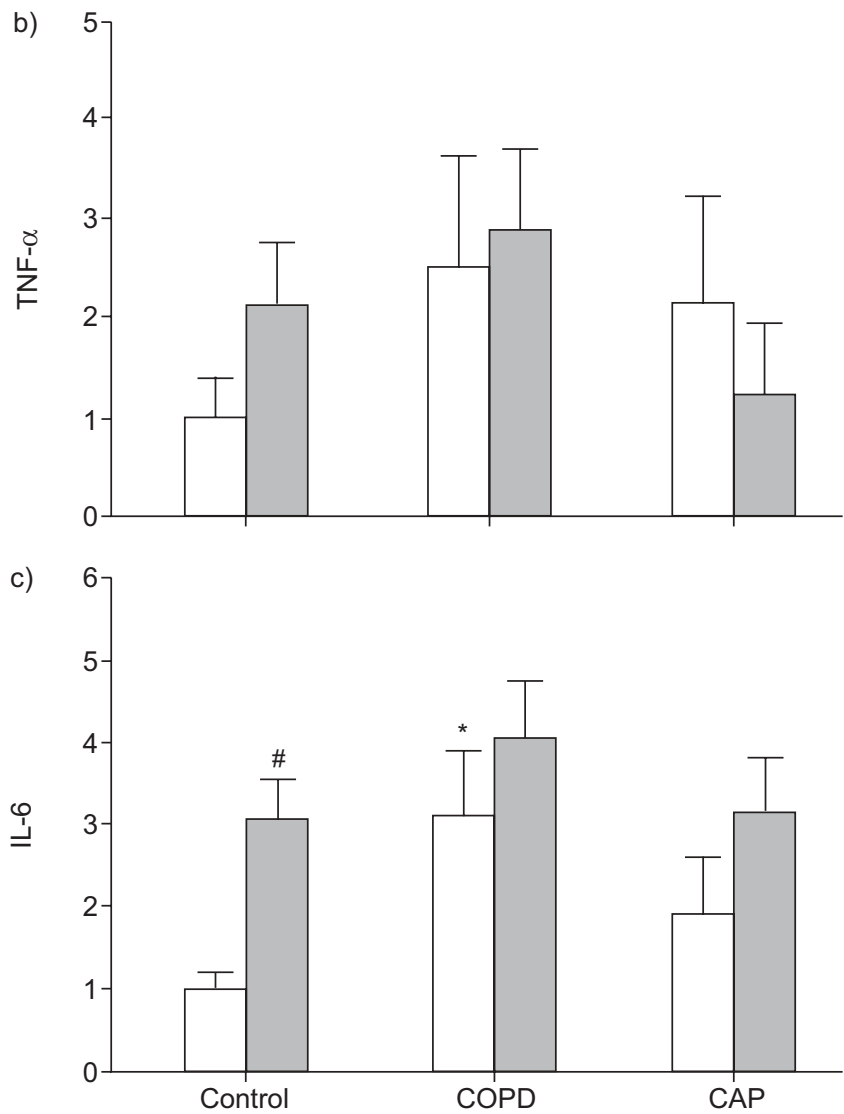

FIGURE 3. a) Lack of CD14 expression in macrophage-differentiated HL60 cells. After tissue plasminogen activator treatment, both THP1 and HL60 cells acquire a macrophage-like phenotype and express CD11b. In contrast, CD14 was expressed only in THP1 cells. b) Effect of lipopolysaccharide (LPS; $100 \mathrm{ng} \cdot \mathrm{mL}^{-1}$ ) treatment on macrophage-differentiated HL60 cells incubated with 20\% sputum for $24 \mathrm{~h}$. Results are expressed as increases with respect to the control group. PMA: phorbol 12-myristate 13-acetate; GAPDH: glyceraldehyde 3-phosphate dehydrogenase; TNF- $\alpha$ : tumour necrosis factor- $\alpha$; IL: interleukin; COPD: chronic obstructive pulmonary disease; CAP: community-acquired pneumonia. $\square$ : nontreated; $\square$ : LPS treated. *: $p<0.05$ with respect to control; $: p<0.05$ with respect to nontreated cells.

the lung may potentiate or inhibit several homeostatic mechanisms involved in the tissue response to aggression [5]. The resulting response may then be deleterious and, in severe CAP patients with previous $\mathrm{COPD}$, it may result in a higher mortality rate than in non-COPD patients. For this reason, the finding that, in a particular group of patients with antibiotic failure, COPD is a protective factor is highly surprising [6]. 
In this case, changes in the lung microenvironment may result in a different cell response to the aggression. In particular, inflammatory and immune cells are highly sensitive to mediators present in the lung, and the particular activation profile has a profound effect on the activation of inflammatory cells in response to the aggression [11].

We tested this possibility by treating macrophage-differentiated THP1 cells with sputum obtained from AECOPD or CAP patients and comparing the activation profile triggered with that resulting from the treatment of these cells with sputum from COPD+CAP patients. Induced sputum has long been used as a noninvasive tool for investigating the airways. It provides the mediators present in the large airways and several reports show a correlation between inflammatory cells and cytokines present in sputum and in bronchoalveolar lavage fluid. In our experimental conditions, the sputum was filtered to avoid the presence of inflammatory cells or microorganisms. Hence, the observed effects are linked only to the presence of soluble mediators in the pulmonary microenvironment. In addition, the use of an unstimulated cell line avoids the interfering effect of previous corticosteroid therapy or other factors that might modify the response of alveolar macrophages from patients.

As expected, macrophages incubated with sputum obtained from CAP patients showed an increased expression of the inflammatory cytokines TNF- $\alpha$ and IL- 6 . This may be associated with the classical M1 activation [20] associated with the antimicrobial activity of macrophages (fig. 1). In contrast, no changes were observed in arginase or mannose receptors associated with the alternative M2 activation of macrophages. These results indicate that there are mediators in the pulmonary milieu that promote the M1 antimicrobial activation of macrophages. Clearly, bacterial products may be involved in this effect, together with different cytokines or lipid mediators that also promote and maintain the M1 response, including interferon $-\gamma$ and other macrophage-derived cytokines that result in a positive pro-inflammatory feedback.

Furthermore, treating the macrophages with sputum from AECOPD patients results in the induction of a clearly different phenotype. In this case, the induction of a response similar to M2 seems to be induced. Macrophages showed an induction of arginase and mannose receptor, and no induction was observed for TNF- $\alpha$, suggesting activation of the alternative phenotype [20]. However, IL-6 is induced in macrophages treated with AECOPD sputum, and IL-6 is inhibited during the characteristic M2 activation. In fact, COPD is considered a Th1 disease, but it is known that some Th2 cytokines, such as IL-4, are also present in greater amounts in bronchoalveolar lavage fluid from AECOPD patients [21]. It is therefore not surprising that the cell response to the sputum was not a theoretical, ideal M1 or M2 profile.

More interesting are the differences observed in macrophages treated with sputum from COPD+CAP patients. In this case, only a moderate, nonsignificant, increase was observed in arginase, mannose receptor and TNF- $\alpha$ expression and only induction of IL- 6 was maintained. This activation indicates the absence of a clear M1 or M2 response in the macrophages.

Of note is the fact that the sputum from COPD+CAP patients induces a different activation of macrophages than the sputum from CAP or AECOPD patients. This is because macrophages play a central role in the regulation of the inflammatory response as well as in the repair processes. Situations that modify the macrophage activation may have a strong effect on the final resolution of the disease process. In the case of COPD+CAP patients, a protective effect may exist due to reduced tissue damage associated with the less intense inflammatory response.

These changes in induction may be related to the presence of bacterial products in combination with the cytokines generated during AECOPD. As indicated, sputum was filtered in order to avoid the presence of cells or bacteria when macrophages are incubated, but the presence of LPS or other bacteria-derived products of low molecular weight may be expected.

To evaluate the effect on macrophage activation of bacterial products in an AECOPD-derived microenvironment, we incubated macrophages with sputum from COPD or CAP patients, and a dose of LPS was added to the cell culture medium. In these conditions (fig. 2), the expression of TNF- $\alpha$ was strongly increased in all experimental groups, indicating that TNF- $\alpha$ expression induced by CAP sputum does not achieve maximum cell capacity. In contrast, adding LPS to the medium increased the expression of IL-6 induced in macrophages treated with control sputum, but had no effect when the sputum was obtained from CAP patients, reflecting the different regulation between TNF- $\alpha$ and IL- 6 . The strong response of TNF- $\alpha$ agrees with that reported by HACKETT et al. [22] using lung tissue explants incubated with LPS. More interesting is the fact that sputum from AECOPD patients clearly induces the expression of IL-6, but the addition of LPS results in an additional induction. This fact indicates that IL-6 induction associated with AECOPD involves mechanisms different from those associated with CAP. It may be that IL-6 expression in macrophages is directly induced by LPS in CAP and by inflammatory cytokines in COPD.

This was confirmed in additional experiments by using the HL60 cell line, which could also be differentiated to macrophages by treatment with tissue plasminogen activator, but that do not express CD14 [18] when differentiated (fig. 3a). As CD14 plays a role in the detection of bacterial LPS, together with TLR [23], the activation observed in these cells must be related mainly to cytokines present in the sputum, with bacterial products playing a far less important role. Under these conditions, the induction of IL-6 in response to AECOPD sputum was maintained but the additional response to LPS was lost (fig. 3b).

This suggests that the microenvironment present in the lung in these pathological conditions is able to modulate the activation of macrophages, resulting in different phenotypes. In patients with COPD+CAP, this phenotype is different from that induced by mediators present in the lungs of patients with either AECOPD or CAP. This different activation may result in a different inflammatory response and may be involved in the different outcome observed when these two entities (COPD and $\mathrm{CAP}$ ) present simultaneously.

From a clinical point of view, the results of this study reopen the debate on short-term mortality of COPD patients with CAP. Since steroids did not affect the results of the study, we 
can speculate that a downregulation in the inflammatory response occurs in COPD patients when they are challenged by a new, acute aggression, such as pneumonia.

\section{SUPPORT STATEMENT}

The present work received funding from the projects SAF2006-08449, FIS041140, La Marató de TV3- 040530 and Ciber de Enfermedades Respiratorias (Ciberes), an initiative of the Carlos III Health Institute, Barcelona, Spain. R. Piñer and A. Torres were supported by: 2009 SGR 911, Ciber de Enfermedades Respiratorias (Ciberes CB06/06/0028), el Ciberes es una iniciativa del ISCIII, Barcelona, Spain.

\section{STATEMENT OF INTEREST}

None declared.

\section{REFERENCES}

1 Peabody JW, Schau B, Lopez-Vidriero M, et al. COPD: a prevalence estimation model. Respirology 2005; 10: 594-602.

2 Torres A, Serra-Batlles J, Ferrer A, et al. Severe communityacquired pneumonia. Epidemiology and prognostic factors. Am Rev Respir Dis 1991; 144: 312-318.

3 Rello J, Rodriguez A, Torres A, et al. Implications of COPD in patients admitted to the intensive care unit by communityacquired pneumonia. Eur Respir J 2006; 27: 1210-1216.

4 Restrepo MI, Mortensen EM, Pugh JA, et al. COPD is associated with increased mortality in patients with community-acquired pneumonia. Eur Respir J 2006; 28: 346-351.

5 Torres A, Menéndez R. Mortality in COPD patients with community-acquired pneumonia: who is the third partner? Eur Respir J 2006; 28: 262-263.

6 Menéndez R, Torres A, Zalacaín R, et al. Risk factors of treatment failure in community acquired pneumonia: implications for disease outcome. Thorax 2004; 59: 960-965.

7 Ewig S, Birkner N, Strauss R, et al. New perspectives on community-acquired pneumonia in 388406 patients. Results from a nationwide mandatory performance measurement programme in healthcare quality. Thorax 2009; 64: 1062-1069.

8 Soler N, Ewig S, Torres A, et al. Airway inflammation and bronchial microbial patterns in patients with stable chronic obstructive pulmonary disease. Eur Respir J 1999; 14: 1015-1022.

9 Perren A, Cerutti B, Lepori $\mathrm{M}$, et al. Influence of steroids on procalcitonin and C-reactive protein in patients with COPD and community-acquired pneumonia. Infection 2008; 36: 163-166.
10 Confalonieri M, Urbino R, Potena A, et al. Hydrocortisone infusion for severe community-acquired pneumonia: a preliminary randomized study. Am J Respir Crit Care Med 2005; 171: 242-248.

11 Martinez FO, Sica A, Mantovani A, et al. Macrophage activation and polarization. Front Biosci 2008; 13: 453-461.

12 Shaykhiev R, Krause A, Salit J, et al. Smoking-dependent reprogramming of alveolar macrophage polarization: implication for pathogenesis of chronic obstructive pulmonary disease. J Immunol 2009; 183: 2867-2883.

13 Rutgers SR, Timens W, Kaufmann HF, et al. Comparison of induced sputum with bronchial wash, bronchoalveolar lavage and bronchial biopsies in COPD. Eur Respir J 2000; 15: 109-115.

14 Frankenberger M, Menzel M, Betz R, et al. Characterization of a population of small macrophages in induced sputum of patients with chronic obstructive pulmonary disease and healthy volunteers. Clin Exp Immunol 2004; 138: 507-516.

15 Mandell LA, Wunderink RG, Anzueto A, et al. Infectious Diseases Society of America/American Thoracic Society consensus guidelines on the management of community-acquired pneumonia in adults. Clin Infect Dis 2007; 44: Suppl. 2, S27-S72.

16 Barberà JA, Peces-Barba G, Agustí AG, et al. [Clinical guidelines for the diagnosis and treatment of chronic obstructive pulmonary disease.] Arch Bronconeumol 2001; 37: 297-316.

17 Anthonissen NR, Manfreda J, Warren CP, et al. Antibiotic therapy in exacerbations of chronic obstructive pulmonary disease. Ann Intern Med 1987; 106: 196-204.

18 Auwerx J. The human leukemia cell line, THP1: a multifacetted model for the study of monocyte-macrophage differentiation. Experientia 1991; 47: 22-31.

19 White SL, Belov L, Barber N, et al. Immunophenotypic changes induced on human HL60 leukaemia cells by 1alpha, 25-dihydroxyvitamin D3 and 12-O-tetradecanoyl phorbol-13-acetate. Leuk Res 2005; 29: 1141-1151.

20 Gordon S. Alternative activation of macrophages. Nat Rev Immunol 2003; 3: 23-35.

21 Barnes JP. The cytokine network in asthma and chronic obstructive pulmonary disease. J Clin Invest 2008; 118: 3546-3556.

22 Hackett TL, Holloway R, Holgate ST, et al. Dynamics of proinflammatory and anti-inflammatory cytokine release during acute inflammation in chronic obstructive pulmonary disease: an ex vivo study. Respir Res 2008; 9: 47.

23 Dobrovolskaia MA, Vogel SN. Toll receptors, CD14, and macrophage activation and deactivation by LPS. Microbes Infect 2002; 4 903-914. 